
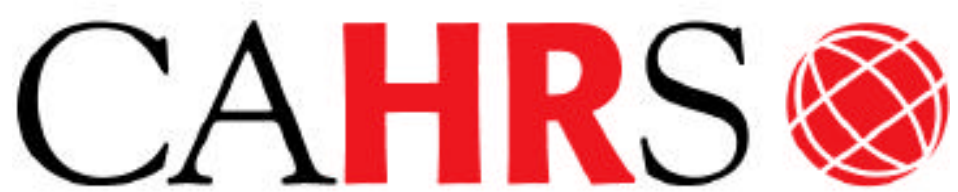

Center for Advanced Human Resource Studies
CAHRS / Cornell University 187 Ives Hall

Ithaca, NY 14853-3901 USA

Tel. 607 255-9358

www.ilr.cornell.edu/CAHRS/

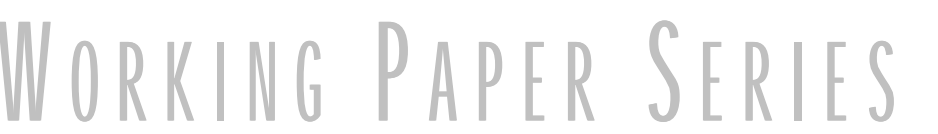

\section{Strategic Human Resource Management Measures: Key Linkages and the PeopleVantage Model}

John W. Boudreau

Working Paper 98 - 28 


\title{
Strategic Human Resource Management Measures: Key Linkages and the PeopleVantage Model
}

\author{
John W. Boudreau \\ Center for Advanced Human Resource Studies \\ ILR School \\ Cornell University
}

Running Head: Strategic HR Metrics and PeopleVantage

\author{
Address Correspondence to: \\ Professor John W. Boudreau \\ Director, Center for Advanced Human Resource Studies \\ Department of Human Resource Studies \\ School of Industrial and Labor Relations \\ Cornell University, 393 Ives Hall \\ Ithaca, New York 14853-3901 \\ Phone: 607-255-9358 \\ Fax: 607-255-4953 \\ email: jwb6@cornell.edu
}

DRAFT ONLY: Please do not quote, cite or distribute without permission from the author

Working Paper 98-28

http://www.ilr.cornell.edu/cahrs

This paper has not undergone formal review or approval of the faculty of the ILR School. It is intended to make results of Center research available to others interested in preliminary form to encourage discussion and suggestions. 


\begin{abstract}
The field of human resource management faces a significant dilemma. While emerging evidence, theory and practical demands are increasing the visibility and credibility of human capital as a key to organizational success, the measures used to articulate the impact of human resource management decisions remain misunderstood, unwanted by key constituents, or even counter-productive. This article proposes that the key to creating meaningful HR metrics is to embed them within a model that shows the links between HR investments and organizational success. The PeopleVantage model is proposed as a framework, the application of the model is illustrated, and the potential of the model for guiding research and practical advances in effective HR measures is discussed.
\end{abstract}


The field of human resource management (HRM) faces a significant dilemma. The idea that HRM must focus on outcomes, rather than solely on programs, activities and costs is becoming well established (e.g., Boudreau, 1991; Milkovich \& Boudreau, 1997; Ulrich, 1998). Moreover, there is a rapidly-growing body of books and articles suggesting that the key to competitive advantage lies with the organization's human resources. Leading management scholars admonish top managers to link the human element of the organization directly into the balanced scorecards, or other overall strategic guidance systems (e.g., Kaplan \& Norton, 1996; Treacy \& Weirsema, 1997). Intellectual capital is widely suggested as an emerging key to organizational success, that is not effectively reflected in standard accounting and financial reports (Roos \& von Krogh, 1996; Petrash, 1996; Sveiby, 1997), and the diminishing correlation between future financial performance and standard accounting measures of value seems to attest to the importance of more intangible factors (Economist, 1998). Leading organizations routinely point to their people as "our most important asset," and the business press is filled with stories demonstrating how people in organizations are becoming increasingly important to future success through creativity, agility, and a "knowledge-based" organization (Boudreau \& Ramstad, 1997; in press).

Indeed, one might well ask, "Is the battle won?" Perhaps we have reached such an advanced state of understanding about the value of human resources and people that we no longer need to develop better models and measures of the impact of human resources? As we shall see below, this does not seem to be the case. While organizations, and even financial analysts, may well recognize the general value of people, we have much work to do before the models and measurements that we use for human resources are adequate. We do not yet have measures that are widely used and understood, and existing measures often fail to support and enhance key decisions about people at work. Effective HR measurement systems should be capable of guiding rapid and appropriate decisions affecting employees, in language that is understood by all key constituents.

This paper will discuss four necessary elements of enhanced HR measurement, and will provide a framework for understanding and developing better future measures. The four components are: (1) Evidence; (2) Explanation; (3) Purpose; and (4) Method. Evidence is required to establish that the effects of human resources are indeed significant enough to merit intensive measurement and study. Explanation is needed to provide a logical reason to suggest why and how human resources create their significant effects on organizations. Purpose refers to the goals of measurement systems, which extend beyond simply developing 
and applying new measurement systems, and must consider the effects of measures on key stakeholders within and outside the organization. Finally, the Method refers to a model and framework to support developing better HR measures. Typically, HR measurement takes the opposite approach, in which the search for better measurement methods is the first, and often the only, step. It is argued here that the method is only the last of the key requirements, and can only be considered after the first three.

\section{The EVIDENCE: Human Resources and HR Activities Have An Organizational Impact}

It makes little sense to measure something of little consequence. So, the first requirement of an HR measurement system is evidence that the human resources and human resource processes of organizations matter to success and survival. Fortunately, a good deal of recent theory and evidence suggests that investments in HRM have significant impact on organizational outcomes. Certain "bundles" of "high-performance" work practices (e.g., performance-contingent pay, team-based work structures, selective recruitment and hiring, extensive training, etc.) seem to be associated with higher organizational financial performance (Arthur, 1992; Becker \& Huselid, in press; Ichniowski, Shaw \& Prennushi, 1997; MacDuffie, 1995; Welbourne \& Andrews, 1996). For example, Huselid (1995) surveyed top HR officers in U.S. organizations to determine the number and type of HR activities in their organizations. He reported that a one-standard-deviation increase in the number of activities was associated with 1.3\% lower turnover, US\$27,044 greater sales/employee, US\$8,641 greater market value per employee, and US\$13,814 greater cash flow per employee (one standard-deviation is approximately equivalent to the difference between being average and being higher than $85 \%$ of the sample). Welbourne \& Andrews (1996) studied U.S. firms issuing their initial public offering of shares (IPO's), and used proxy statements to measure the emphasis on HRM (e.g., providing stock options to all employees, having an HR officer, or stating in the proxy that human resources are a key to competitive advantage). They found that this index was positively associated with share price and survival over five years. Many companies and consulting firms routinely compute correlations between human resource activities or worker attributes, and unit or organizational performance, for example, between employee attitudes and customer satisfaction. Such correlations beg the question of the causal direction and the possibility of omitted variables, leaving many unanswered questions. It remains possible that these strong associations with surveys of HR managers about their firm's practices may reflect merely their individual concept of what practices associate with firm performance.

Copyright $\odot 1998$ John W. Boudreau and PeopleCOM. Please do not quote or cite without permission 
Nonetheless, the increasing attention to such evidence from organizations and consulting firms illustrates the popularity of the idea that human resource attributes may associate with organizational profits or other key strategic outcomes. Boudreau \& Ramstad (1997) review other studies showing similar results. Thus, emerging evidence from samples of many organizations seems to support the assertion that human resources, and the activities associated with managing human resources, do indeed associate with tangible investment returns.

Some organizations have begun to map very precisely the linkages between human resources and organizational performance, especially organizations with very direct relationships with customers. Sears, in the U.S. (Rucci, Kirn \& Quinn, 1998) is one such example. In this large retailer, top managers carefully measured employee attitudes, employee behaviors with customers, customer reactions to those behaviors in terms of perceptions of service and merchandise, and customer behaviors such as repeat purchases, etc. By measuring these phenomena across over 800 stores and over time, the power to detect relationships was significant. Among the findings were: Increasing store associates' attitudes toward their job by 5 units increased customer impression by 1.3 units; and Increasing customer impression and retention by 1 unit is associated with revenue increases of $.8 \%$ in the current period.

The Sears results not only provide additional evidence of the potential impact of people on organization success, but also illustrate the importance of having a model and a framework to guide the search for measures and relationships. Without a model of how people affected value, it would have been impossible for Sears managers to analyze the massive amounts of data on employee characteristics, shopper reactions and store performance. The logic guiding the analysis is as important as the power of the data. This brings us to the second key component of a measurement system, an explanation for the impact of people on organization success.

\section{The EXPLANATION: Sustainable Competitive Advantage}

These results are tantalizing, but without a more general theory about why such effects occur, we cannot build and act on them. Is there good reason to believe that people could have such a significant impact on organization results? How can we explain these results in ways that guide us toward appropriate measures? While it is beyond the scope of this paper to attempt a theory of the value of people to organizations, it is worth noting that there are 
emerging frameworks that suggests why and under what conditions people can make a significant impact.

One of the most prominent frameworks, especially among writers in the area of strategic human resource management, is the "value-based" theory of competitive advantage, which suggests that sustainable competitive advantage is created through resources that are "VRIO": Valuable, Rare, difficult to Imitate, and supported by Organizational structures that allow them to be exploited effectively (Barney \& Wright, 1998). All of these factors are necessary for a resource to create sustainable competitive advantage, that is not easily imitated by competitors. Barney \& Wright (1998) and Coff (1997) give several examples showing how human resources can contribute to sustainable competitive advantage. The idea is that precisely because the factors that make human resources valuable are difficult to measure, somewhat uncertain, complex, and contain many intermediate linkages that must occur, people represent a key source of competitive advantage. When an organization can exploit resources that have such complex relationships, it is very difficult for others to copy them. The key is related not just to the resources themselves, but to the ability to use resources to strategic advantage (Stalk, Evans \& Shulman, 1992). The theory of "high performance work systems" relies on mounting scientific evidence that certain "bundles" of "high-performance" work practices (e.g., performance-contingent pay, team-based work structures, selective recruitment and hiring, extensive training, etc.) are associated with higher organizational financial performance (Arthur, 1992; Becker \& Huselid, in press; Ichniowski, Shaw \& Prennushi, in press; MacDuffie, 1995; Welbourne \& Andrews, 1996). This perspective suggests that it is the synergy of these practices working together that creates the elements of strategic advantage. Finally, it has been suggested that intellectual capital may explain the impact of people on organizations. The theory suggests that intellectual capital is embedded in the individuals, relationships within the organization, and relationships with customers (Sveiby, 1997). Moreover, it has been suggested that both the stock and the flow of such intellectual capital explains the ability of organizations to build on their intellectual capital assets, and to exploit those assets in unique ways to achieve competitive advantage.

Thus, these three theories, taken together, explain how human resources can indeed be a source of organizational competitive advantage. While they may not offer a complete explanation, they capture logical mechanisms that suggest the potentially high value of human resources. Moreover, they also explain why this value is not well captured in the traditional measurement systems of organizations. As Boudreau and Ramstad (1997) pointed out, 
traditional organizational measurement systems proceed from a model in which physical and financial capital are the most important resources, and so they are ill-suited to capture the complexities of human contributions to the organization. A useful measurement framework for human resources will need to provide a mechanism for capturing the linkages between investments in people and organizational outcomes, as well as help to identify where the important investments should be made.

\section{The PURPOSE: Enhancing Key Stakeholder Reactions and Decisions}

With both evidence and explanations in place, we have established that the value created by human resources is potentially significant, and that it emanates from logical and predictable processes. However, we have few measurement frameworks designed to capture these processes and their link to organizational performance. Moreover, there is evidence, discussed next, to suggest that key constituents like financial analysts do not find existing HR measures useful. This brings us to the second element of a strategic measurement system, the purpose. We must identify clearly what a strategic HR measurement system is designed to accomplish.

Boudreau (1995) noted that HR metrics create value (or harm) according to their effects on key constituencies, suggesting that metrics research adopt a "choice" model of HR measurement, in which such systems are adopted based on communication goals and probable receiver responses (Shelby, 1988, 1991). Boudreau noted how HR metrics could be used to persuade, support decisions, or can even be considered fashion-setting devices. Metrics are not neutral, and the choice of metrics conveys values, priorities and a strategic framework. Metrics reflect an implicit constituency. Consider the strategic decisions involved in mergers and acquisitions. The measures used to guide such decisions virtually always reflect resources such as capital, markets, technology, brands, etc. They frequently omit any explicit index of human factors, and are often presented as a method of shedding extraneous labor. Thus, whether intentional or unintentional, the choice of HR metrics sends signals that will affect the impressions and decisions of many organization constituents. To be "strategic," metrics must enhance decisions or other valued outcomes for key strategic constituents. Constituents typically considered are the shareholder or client for human resource outcomes (usually a line manager), but in fact metrics will send signals and likely affect the behavior of a broad set of constituents including employees, unions, governments, communities and customers . 
There are disturbing indications that significant hurdles remain to be overcome. Key constituents in the financial community and elsewhere appear to lack the ability evaluate the quality of HRM programs and investments, and the resulting quality of the human capital of the organization. Evidence on investor behavior is admittedly sparse, but the existing handful of studies has examined this issue paints a bleak picture. For example, the Welbourne \& Andrews (1996) study of IPO's cited earlier found that the same index that positively predicted five-year survival and share price was negatively associated with the initial price set by financial analysts! Similarly, Eccles and Mavrinac (1995) surveyed financial analysts, corporate managers and portfolio managers, and found that "information about employees (e.g., employee satisfaction, training levels and expenditures, and turnover rates) is least actively communicated by managers, least desired by analysts and investors, and considered least important by all three groups in evaluating performance." (p. 19). In contrast, Low and Seisfeld (1998) studied the investment decisions of analysts and found "Analysts showed the greatest interest in customer and product-related factors--things like market share, customer retention and marketing - with only slightly less interest in internal and employee-related factors (production, efficiency, empowerment, incentive compensation) and innovation-related factors (training, R\&D, and product development)." Moreover, they found that "when nonfinancial factors were taken into account, earnings forecasts were more accurate, thus reducing the risk to investors." (p. 27). Yet, we know little regarding how analysts do or should integrate such information.

This lack of knowledge is by no means due to a lack of available measures of HRM activities, costs, investments and returns. An increasing number of frameworks exist for measuring intellectual capital and reporting it in a form similar to other financial information. It is suggested that the significant and increasing difference between the financial book value and market capitalization value of corporations is due to the growing importance of things not measured by the financial book value, requiring new statements reflecting intellectual capital or intangibles. Leading organizations such as DuPont and Skandia have implemented such systems, adding even more new measures to a field already struggling to apply systems such as human resource accounting, behavioral costing, human resource costing, competencybased inventories, and a host of other measurement systems.

The HRCA literature is replete with models for estimating the currency-valued payoff from HRM investments (e.g., Boudreau, 1991; Mabon, 1996; Klaas \& McClendon, 1996), which begin with HRM programs such as compensation, staffing, training, turnover control, etc. 
and work outward to estimate the impact on currency-valued outcomes. The literature is also filled with methods for estimating the costs of key human behaviors at work, such as turnover, absence, theft, etc. (e.g., Cascio, 1991; Fitz-enz 1995), which usually reveal such behaviors as being quite costly, justifying rather sizable investments to curtail such behaviors, in an effort to reduce these costs. Yet, even here, recent studies from industrial/organizational psychology suggest that in laboratory experiments with hypothetical training investments, management trainees who were provided with elaborate calculations of the dollar value of investments were actually significantly less likely to report they would invest in the new program than managers given simply descriptions of the same program without the additional calculations (Latham \& Whyte, 1994; Carson, Becker \& Henderson, 1998). In sum, it appears from empirical evidence and analyst performance that accounting for the impact of HRM is possible and informative, yet actual managers and analysts appear unable or unwilling to use existing information profitably.

So, it appears that there is a significant disparity between the admonishments of scholars and consultants (who are recommending and developing a plethora of measures of human and intellectual capital, human resource costing and investment measures), compared to the practical use of these measures to drive financial and strategic decisions. Also, while there is evidence of the impact of $\mathrm{HR}$, there remains little knowledge regarding the specific $\mathrm{HR}$ processes that contribute to these associations. HR metrics are a key to providing this knowledge. We should hold our metrics to a high standard. If they are truly effective, then they should help organizations: (1) Make fewer mistakes in their human resource investments (fewer "dumb things" in the words of Pfeffer, 1996); (2) Achieve greater adaptability and agility; (3) Logically align HR investments and key organizational outcomes; (4) Enhance decisions and understanding among key constituents; and (5) Create a more consistent match between the "agents" of the organization (employees and managers) who must act on behalf of the "principals" or key constituents (owners, communities, and societies).

\section{The METHOD: PeopleVantage}

This section describes a measurement framework designed to address these questions. This framework, takes as its inspiration the concept of a vantage point, from which a broad but comprehensive picture can be seen. The model is called PeopleVantage, owing to its focus on how the human elements of the organization-- the people -- contribute to success. HR metrics must articulate the full complement of linkages between investments in $\mathrm{HR}$ activities and their outcomes (Boudreau \& Ramstad, in press), so that there is less disparity 
between the development of impact-related HR measures and their understanding and use. Kaplan \& Norton (1996) proposed that a measurement system should embody a "theory of the firm," with measures serving as ongoing tests of that theory, and indicators to show when the theory or the outcomes need to change. This means that the measurement framework should express a theory of the firm through linkages from people to organizational outcomes. HR metrics are not simply an evaluation tool, or a method of justifying HR investments. Rather, they represent the operational expression of the theory of how people contribute to organization success, and the HR investments that lead to that success. This can best be illustrated through an example.

\section{An Illustration: What is the job of a sweeper at a Disney theme park?}

Consider your last visit to one of the Disney theme parks, such as Disneyland and Disney World in the U.S., or EuroDisney in Europe. Recall when you needed to ask directions to a certain park location, perhaps a particular event, a place to eat, a bathroom, etc. Did you go up to one of the major Disney characters to ask your question? Most people don't ask Snow White, Arielle, Mickey Mouse or Goofy such questions. In fact, most people will ask one of the more anonymous workers at the park, such as a restaurant worker, shopkeeper, clerk or the "sweepers" who clean the grounds. Disney is world-famous for the investments that it makes in training its employees, and for its philosophy that all employees are "characters" on the stage of the theme park. Few realize, that this also extends to the anonymous employees, the sweepers and their type. It is easy to see how the people playing major characters or the performers in the shows fit this vision, but how does a "sweeper" become a "character" essential to the strategic vision of the park? The key is in the fact that park visitors interact with "sweepers" when they need information. One often hears patrons say, "I couldn't believe how knowledgeable and friendly the groundskeeper was. S/he was eager to answer our question, and was very well informed. Even though it wasn't part of their job, they took the time to really help us." In fact, such helping is a key part of the job of "sweepers" at Disney.

Traditionally, organizations define jobs by focusing on the specific tasks of the worker. Thus, a "sweeper" is defined as someone who sweeps, picks up trash, etc. Based on this logic, one would hire sweepers for minimal skills in cleaning, recruit from among those who are willing to work for the minimum wage, and provide only basic training in the use of equipment. Rewards would probably be based on time on the job and, at best, performance would be evaluated by such things as reliable attendance, and perhaps the cleanliness of the person's assigned territory in the park.

Copyright $\odot 1998$ John W. Boudreau and PeopleCOM. Please do not quote or cite without permission 
At Disney, "sweepers" are selected, trained and rewarded for their friendliness and courtesy to customers, and their ability to provide useful information when asked. It is no accident that patrons at Disney theme parks have such good experiences with the "anonymous" workers in the park, because Disney recognizes the critical behaviors and "moments of truth" that make a park visit a customer's delight. Of course the attractions, shows and characters must be excellent, but in many ways these things can be copied by others. So, it is also critical that the "sweepers" and others like them "perform" excellently when they come in contact with customers. Other theme parks miss this critical point, and continue to define the job of "sweeper" merely in terms of sweeping, so it should be no surprise that Disney can achieve a competitive advantage. Notice how differently one would approach the measurement of the impact of human resources "sweepers" in the Disney framework. Even investments in sweepers are measured according to their impact on the delight of theme park customers.

\section{Lessons from the Disney Example: Linkage and Constraints}

It is tempting to dismiss the Disney example as applying only to employees in a theme park. However, the lessons apply to all employees who routinely meet customers. Indeed the example has important messages for workers in these situations. Leading organizations have begun to understand the importance of discerning the impact of all employees on the most critical organizational outcomes. For example, Pepsi Cola invests in cultural training and provides strategic market information not only for its managers, but for employees such as the truck drivers who deliver product to vending machines and retail stores. The logic is that the truck drivers are the "face" of Pepsi Cola to key customers, and the "moments of truth" that make a difference between missing or gaining a sale are often under the control of these employees. Delivery drivers who are friendly and informative with supermarket managers sell more product. Vending machines and store displays carefully and neatly maintained so that the product "faces" the customer (the brand name is clearly visible) are more eye-catching and result in more sales. Moreover, these lessons also apply to organizations with employees who may never meet a customer. In another "sweeper" example, Jay Barney (1997, personal communication) notes that in one organization he approached a janitor and asked what the organization's mission was. Surprisingly, the janitor accurately stated that the mission was to provide customer intimacy through world-class delivery of their key products. The more difficult question came next, "Can you make a difference to this mission in your work?" The 
custodian proceeded to state that he altered his cleaning routine to emphasize those parts of the manufacturing plant where dirt was most likely to produce product flaws and failures or injuries. Deciding where to clean represented a moment of truth because the cleaning pattern affected other employee work processes that directly supported the value proposition. Again, notice how this changes the nature of HR metrics. Rather than measuring the time to fill janitorial vacancies, the wage costs of janitors, and perhaps their turnover rates, appropriate HRM metrics might determine how differential cleaning relates to objective outcomes such as machine failure, or the perceptions of employees who benefit from these janitorial services. Two themes run through these examples: Linkage and Constraints. These themes provide significant guidance for the future of HR metrics.

Linkage. Linkage refers to the clarity of connection between the investments made in human resources, and the effect of human resources on organizational outcomes. As Boudreau \& Ramstad (in press) have noted, linkage is a key missing element in many theories of strategic human resource management. Yet, it is key to identifying the critical HR measures and their effects on key constituents. In the Disney example, the sweepers can very clearly link their behaviors to the ultimate mission of the theme park, "delighted patrons." Disney helps sweepers understand that while sweeping well is important to this mission, it is also imperative that patrons have a friendly and informative experience with the sweeper, because that experience affects their impression of the visit, and those impressions affect their desire to spend money and to visit the park again. An HR measurement system should be built on the principle of linkage, so that every HR metric can be shown to reflect a key linkage between human resource investments and organizational outcomes. The PeopleVantage framework that follows is one way to describe this linkage.

Constraints. Constraints represent the key bottlenecks between success and failure. While constraints are often seen as negative factors, they are actually quite valuable in designing HR metrics. Boudreau \& Ramstad (1997) noted that constrained resources offer the greatest opportunity for improving organizational success. Consider an organization with a great deal of product in inventory, and plenty of production capacity. The key constraint to organizational success is the lack of sales, not the lack of production. In such organizations, it is quite typical for HR managers to very diligently work to improve production efficiency through training, incentive pay and teams, and even to calculate elaborate dollar values based on the presumed selling price of the output. Yet, the key place to invest is in the sales area, and the key measure of success is to reduce the inventory. Only when inventory is reduced does the 
production constraint become meaningful. In the Disney sweeper example, the wisdom lies in understanding that the key constraint is the number of opportunities to delight a patron. The key constraint is not "well-swept grounds" though that is important. Rather Disney sees their mission as providing a delightful experience at every opportunity, and recognizes that many of these opportunities occur when people approach the sweepers.

Thus, constraints are not unpleasant facts to be avoided, but opportunities to be embraced. We should "celebrate" the constraints as a guide to the key HR metrics. It is not uncommon to see significant HR resources non-optimally applied due failure to appreciate the idea of constraints. For example, organizations that have difficulty acquiring raw materials, but little trouble selling their product frequently continue to devote significant resources to motivate sales volume, while at the same time motivating procurement to focus on getting the best price for raw materials. In fact, as Ramstad (1998 personal communication) has noted, if the key constraint is the raw materials, it makes sense for HR to encourage procurement to focus on volume ("get the raw materials even if you must pay more"), and sales to focus on price ("only sell to those willing to pay a premium"). Thus, through linkages and constraints, an HRM measurement process should be a mechanism for articulating linkages and for connecting decisions about people to the key strategic constraints facing the organization. We now introduce the PeopleVantage model as a framework illustrating this approach to HR metrics.

\section{PeopleVantage Model}

Figure 1 presents PeopleVantage model graphically. Beginning at the bottom of the diagram, human resource activity "bundles" support and create human attributes of Capability, Opportunity and Motivation (COM). These attributes enable employees to enact critical behaviors that represent the "Moments of Truth" experienced by key constituents. These moments of truth affect constituent perceptions and reactions, forming the basis for successfully accomplishing the key "Business Processes" of the organization, including "new product introduction," "market intelligence," "productivity/quality," etc. Finally, the successful execution of the business processes leads to success in achieving the value propositions. Examples include "operational excellence," "product leadership," and "customer intimacy" (Treacy \& Weirsema, 1997). 
Figure 1. PeopleVantage Model Integrating Human Resource Metrics and Strategic Human Resource Management

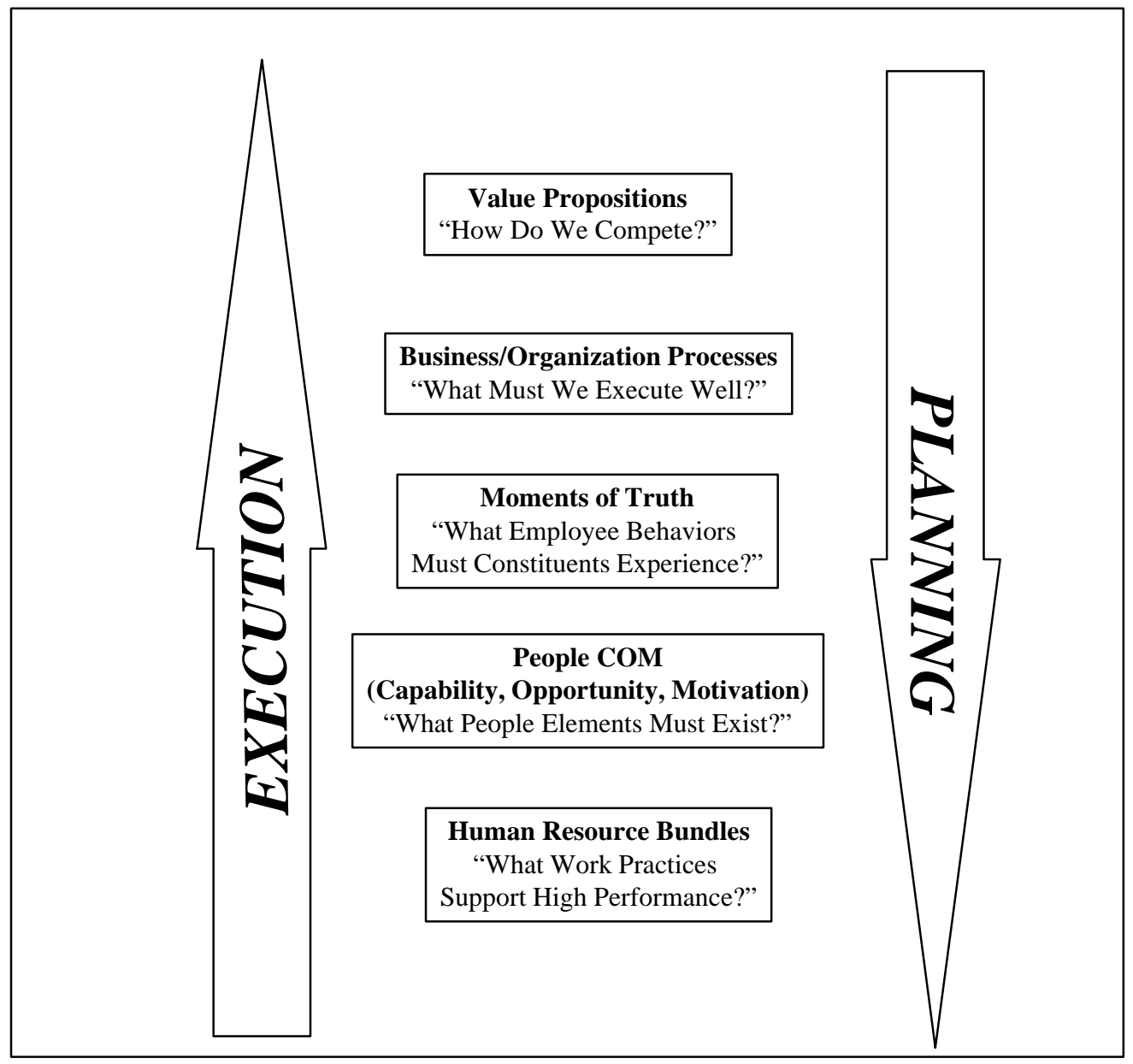


Notice the two arrows in Figure 1. They are meant to convey the synergy between strategic planning, measurement and execution. When planning, the development of metrics proceeds downward, from the value proposition to the bundles. However, when executing the strategy, the causal direction moves upward. Similarly, metrics should be designed based on the strategic vision embodied in the value proposition, and work downward to articulate evermore specific outcomes, but actual implementation of metrics systems will frequently involve tracing linkages from the bottom up. Recall the example of the U.S. retailer, Sears. Their analysis model was based on a top-down concept of becoming an attractive investment for shareholders, supported by customers who experienced good value and service, which are created by employees whose behaviors delight the customers. On the other hand, the metrics that Sears developed began with the employee attributes (e.g., knowledge of the business, motivation to care about customers), and worked upward to measure employee behaviors toward customers, customer reactions, and the impact on revenue. Moreover, the effect of metrics is often best measured at all levels, because key constituents are likely to exist at all levels (Boudreau \& Ramstad, in press). Let us now describe the elements of the PeopleVantage model, beginning from the top of the diagram, using the Disney "sweeper" example.

\section{The Value Proposition ... How do we Compete?}

Kaplan \& Norton (1996), drawing on Porter (1985), define the value proposition as "the attributes that supplying companies provide, through their products and services, to create loyalty and satisfaction in targeted customer segments." Treacy \& Wiersema (1997) distinguish "Operational Excellence," "Product Leadership," and "Customer Intimacy," suggesting that successful firms will choose to excel in one, and meet competition in the other two. These are valuable ideas, but how can we translate them into meaningful decisions about human resource processes? Such generic definitions seem ill-suited to help define strategic HR practices and outcomes. Indeed, it is usually the case that company-wide goals such as these are simply too generic and vague to guide specific HR decisions. At the same time, defining value too narrowly, such as whether trainees increased their knowledge or products, without measuring the effects on the organization's value-creating capacity, is also not useful. The PeopleVantage model may suggest a diagnostic approach to identifying the right level of detail for actionable value proposition. Figure 1 suggests that the appropriate level of value definition will be determined by asking, "can we articulate a coherent linkage from employee behaviors to value creation, using this value proposition?" If the answer is no, then one 
proceeds to the next level of specificity. The model thus may assist HR managers to work with key leaders to help articulate a value definition that can enhance decisions about people.

In the Disney "sweeper" example, a key value proposition in the theme park is "visitor delight." This is the reason why visitors will choose Disney over other theme parks, and "delight" is the key value that is delivered to visitors. Considering the concept of "constraints," Disney recognizes that there is a finite number of chances to delight visitors, and that many of those opportunities occur when visitors interact with the "anonymous" cast members in the park. By recognizing this as a key constraint, and then by focusing human resource investments to address it, Disney enhances the customer delight value proposition. From the standpoint of metrics, what are the likely indicators of success at value creation? Kaplan \& Norton (1996) suggest such while metrics must link to the financial outcomes of the organization, they cannot be limited to financial outcomes, which often lag success. They suggest adding customer satisfaction, retention, new customer acquisition, customer profitability and market and account share.

\section{Business Processes ... Initiatives for Achieving Value}

With value-proposition metrics established, it is possible to "drill down" to identify the business processes that logically support the value propositions. In the Disney "sweeper" example, the key business process is total quality management. Rather than applying these principles to manufacturing, however, the idea at Disney is to build a quality customer service process, so that defects in customer service are eliminated or significantly reduced. If sweepers are equipped to quickly answer questions, provide a friendly and reassuring face, and seek out opportunities to help visitors, then visitors are less likely to experience the "defects" of being unable to find what they need or encountering an uninformed or unfriendly employee. Variability in customer service (especially harmful variability) is thus reduced.

What metrics would indicate that the business or business unit is achieving results that will lead to the value propositions? Typical HRM measures frequently focus only on HR activities, suggesting that these activities represent the key business processes of HR. For example, classroom training is frequently "measured" by the number of courses offered, the number of trainees signed up for each course, or the immediate reaction of trainees upon completing the class or reducing the training costs associated with the class. Such metrics signal that more training courses, large class sizes, low training costs, and positive reactions are the goal. It should not be surprising, then, that many organization leaders perceive at best a tenuous link between training and changes in individual, unit and organizational 
performance. Alternatively, GE, Motorola, Federal Express and others are famous for requiring that training be tied to the key initiatives of the organization, and that it be evaluated as such. Training metrics include the effect on such things as product quality, cycle time, cost reduction, and speed of execution. In several shipping companies, the benefits of enhanced training or selection is frequently expressed as "the number of additional trucks/planes that can be loaded for free, without paying for additional labor." Steve Kerr, Vice President of HR at GE says they "teach the initiatives" (Frost, 1997, p. 341), not just the learning objectives.

\section{Key Behaviors and "Moments of Truth"}

The value propositions and business processes are the typical dependent variables in traditional business and economic research, and have received a significant amount of theoretical and empirical attention. However, the "moments of truth" have received relatively less attention. Gronroos (1990) and Carlzon (1987) noted that "moments of truth" represent pivotal contact points between employees and customers, whether in providing a service, selling a product, or providing assistance. These determine constituents' perceptions of service and product quality.

In the Disney example, the moment of truth is when the visitor approaches the sweeper to ask a question or request assistance. By recognizing the fundamental value propositions and business process, Disney avoids the mistake of defining the moment of truth in terms of the obvious job description. In many organizations, the job of sweeper would be defined in terms of sweeping behaviors, yet this often fails to make a link between the moments of truth and the key business processes. In terms of HR metrics, this suggests that performance metrics for Disney sweepers will reflect customer service, and accuracy of answers to questions. While cleanliness of the park is also important, it is not the exclusive moment of truth. In the classic case of employees meeting customers, the link may be quite clear. Some of the best empirical examples of the links in Figure 1 come from areas where such sales associates meet customers (e.g., Rucci, Kirn \& Quinn 1998).

What is often overlooked is that the "moment of truth" concept applies to situations even without a direct customer meeting. Recall the earlier example of the janitor in a factory, who defined his "customer" as the production workers whose safety and productivity could be enhanced by the way he cleaned the facility. An HR metric system can use intermediate perceptions of internal customers to articulate linkages. If organizational success is built on hundreds or thousands of small steps taken by many employees, it is not enough to articulate a grand value proposition supported by key business processes. Usually strategic success 
depends much more on specific reliable behaviors from thousands of employees (Pfeffer, 1996). Employees need to know what behaviors make a difference. Figure 1 suggests that HR metrics must include such "moments of truth," so that HR leaders and other employees can be held accountable for them.

\section{Capability, Opportunity, Motivation (PeopleCOM)}

At this level of Figure 1 we begin to consider metrics focused on individual and group characteristics. Capability is the capacity of employees to create value; (2) Opportunity is the necessary circumstances for employees to create value; and (3) Motivation is the drive or force employees feel to create value. These three components (COM) are familiar in classic psychological models of human resource management, suggesting that individual performance is a multiplicative function of ability and motivation (Vroom, 1964; Maier, 1955; Cummings \& Schwab, 1973), as well as critiques of the simple model (Campbell \& Pritchard, 1976), and suggestions that the nature of the environment determines the expression of ability and motivation (Gilbreth 1909; Dachler \& Mobley, 1973), and research suggesting that situational constraints and opportunity are key to a theory of work performance (Peters \& O'Connor, 1980; Blumberg \& Pringle, 1982).

In the example of the Disney sweeper, the difference between a strategic approach and a traditional approach are perhaps most apparent in the elements of COM. Traditionally, organizations would consider metrics for the role of sweeper from the "inside out," or by starting with the job of sweeping and then amassing the capabilities required to be an effective sweeper, setting pay and reward levels to motivate conscientious sweeping, reliable attendance and other job-specific behaviors, and providing opportunities only for good sweeping, perhaps by shifting workers to those areas with the most trash. Or, by adding trashremoval capabilities (e.g., the ability to drive a trash removal truck) to the list of job requirements. By using the PeopleVantage model to link the sweeper role to moments of truth, business processes and the value proposition, we see that the appropriate COM for the job of sweeper encompasses much more. For competitive advantage, one would want sweepers with the COM necessary to provide exceptional customer service. Capabilities might include knowledge of the park facilities, talent for effective communication, and ability to provide a friendly demeanor. Rewards would be oriented to motivate sweepers to be alert for chances to help visitors. The traditional approach might lead sweepers actually to avoid park visitors in an effort to concentrate on trash removal. Opportunities are enhanced by placing sweepers in places frequented by visitors. Rather than adding trash-removal duties, Disney 
might install state-of-the-art trash removal technology that allows the sweepers to minimize the time they spend carrying trash, so as to maximize their time in contact with visitors to the theme park.

This suggests that HR metrics should reflect all three components, as all three may be required for human resources to contribute to organizational value. Moreover, any single or set of HR activities may contribute to any of the three components. For example, more stringent selection might be used to identify and hire workers with experience working in teams. At the same time, these workers may have such experience because their needs and values tend to create motivation in team settings.

The concepts of "capability" and "competency" occur frequently in the human resource literature. The vast majority of measures at this level seek to capture the capability element, as seen in the abundance of competency models, and the emphasis on "organizational capability" (Amit \& Shoemaker, 1993; Collis, 1994; Kamoche, 1996; Lado \& Wilson, 1994). While these authors quite appropriately note that these factors combine to create a capacity for strategic change, the emphasis often seems to be on what Figure 1 defines as capability, with less attention to motivation and opportunity. The metrics model suggested here emphasizes that the requisite human attributes go beyond capability, and that an overemphasis on capability may be counter-productive.

What about employee attitudes? Figure 1 does not explicitly incorporate employee attitudes, such as job satisfaction, focusing instead on their effects on employee motivation to engage in behaviors ("moments of truth") such as turnover, citizenship behavior, etc. Recent employee attitude research supports this view that strategy and linkage are key (Johnson, 1996; Ryan, Schmit \& Johnson, 1996; Schmit \& Alscheid, 1995; Schneider, Ashworth, Higgs \& Carr, 1996). There seems to be a trend in these studies to link attitudes with organizational and strategic goals. Organizations, such as GE and Sears have implemented employee "attitude" surveys that reflect a linkage concept. For example, employees might be asked their perceptions that leaders have communicated clearly the vision (value propositions, business processes and moments of truth), that resources are sufficient to accomplish goals, that there is an emphasis on winning, that individuals clearly understand their personal role in meeting objectives, and the rewards that will emanate from achievement (e.g., Rucci, et al., 1998). This kind of measurement seems more likely to show relationships through the value propositions than typical generic measures of job satisfaction. 
A similar approach might be taken toward other common HR metrics. Capability indices such as competencies, skills, knowledge, certification, and test scores can be strategic metrics, but only when embedded within a theory that links them to value. This will help to identify the capabilities that are strategic, and to focus research and practice on developing them. Opportunity indices such as team composition, organizational design, etc. can also be developed based on their linkage. Boudreau \& Ramstad (1997) give several examples of linking COM measures to key organizational initiatives.

\section{Human Resource Management Processes ... The Bundles}

The word "bundles" in this element of the PeopleVantage model reflects evidence that human resource activities are most effective when bundled into synergistic combinations (Arthur, 1992; Huselid, 1995; Ichniowski, et al., 1997; MacDuffie, 1995). Such bundles have sometimes been called "high performance work systems."

The example of the Disney sweeper illustrates this vividly. When we see the sweeper job in terms of its role in the key moments of truth and business processes related to delighting visitors, the array of HR practices appropriate for this role looks quite different from the traditional programs designed to promote only sweeping. Appropriate rewards in light of the customer service role might include incentives tied to high customer satisfaction, and measures of interactions with park visitors. Appropriate selection systems might emphasize finding people predisposed toward service and friendly personalities. Training for sweepers might incorporate the fundamentals of customer interaction and personal relations. This is a far different vision of the bundles than a traditional approach to the job of sweeper, which might focus only on paying for reliable attendance and time worked, and limiting training to the skills needed to use cleaning equipment and supplies.

This perspective suggests a change in the notion of an "HR program" in metrics research and development. Though HR programs typically are measured as relatively largescale interventions applied to many employees, (e.g., formal training, compensation, selection or recruitment), there is "human resource management" occurring in each interaction between employees, managers and customers. How much of the effectiveness of staffing, for example, rests with the individual judgments that are made after candidates have been screened through formal evaluation procedures? How much of the effectiveness of rewards rests with the individual recognition, appraisal and communication that goes on outside the formal pay and performance appraisal processes? How much of knowledge and skill acquisition takes place on the job, independent of formal training programs? Capturing these effects requires 
an approach to metrics that explicates linkages at levels beyond individual HR programs, and that flexibly measures the HR programs themselves. In the PeopleVantage model of Figure 1, it is suggested that HR measures can be derived only after specifying the linkages between the HR bundles and value creation. The typical approach to HR measurement often begins with the programs and attempts to identify measures that capture them. This often results in measures reflecting activities and costs, rather than impact and value.

\section{The Potential Value of the PeopleVantage Approach ... Optimizing, Goal Setting and Persuasion}

The Peop/Scape model thus suggests that in all aspects of measuring the impact of people, there should be a clearly-articulated logic showing which level of the process is represented by the metric, and how that metric links to the other key elements of the model, leading to organizational success. We have proposed that this has the potential to help organizations obtain strategic perspectives that are much more than rhetoric. Moreover such an approach has the potential to create HR measures that can be linked logically and directly to outcomes of interest. Today, it is often impossible to measure every aspect of the PeopleVantage model. Still, by articulating the linkages and adopting measurement systems consistent with those linkages, HR metrics will begin to represent coherent theories showing how people add value in organizations. This is important not only to enhance the quality of the measures so that they better capture the impact of human resource investments. It is also important if HR metrics are to persuade line managers and others of the value of those investments. Finally, metrics derived from such an approach have the potential to better motivate appropriate behaviors among employees, and to communicate effectively with key constituents. We now describe several promising potential ways that this approach can enhance organizational performance, and where future research would appear to be most promising.

\section{Multi-Level Optimization}

As Boudreau \& Ramstad (1997, in press) have pointed out, one of the most powerful and underdeveloped aspects of HRM measurement is the opportunity to optimize the investment in HRM. Traditionally, HR metrics have focused on demonstrating the value of investments in particular programs. The concept of optimization reflects the idea of "bundles" of HR investments, and simply means attempting to achieve the best balance of returns and costs, given the unique payoffs from various individual programs. The concept is well- 
developed in engineering and business. For example, inventory control models have, for many decades, been based on the idea that inventory carries certain holding costs, and also has a certain value when sold. Given knowledge of holding costs, likely demand patterns, and the marginal profit generated by each unit of sales, it is possible to calculate the optimum quantity of inventory to order, which will achieve the lowest combination of holding costs, profit, and risks of lost sales because of being out of stock when an order arrives. Similarly, linear programming models have been used for decades to calculate the appropriate combination of different production inputs or production processes, to maximize the productivity and profit of production. In concept, it should be possible to apply such models to HRM as well. For example, one can imagine models that would optimize the level of certain competencies among employees, considering the various mechanisms through which employees might acquire those competencies (e.g., recruitment/hiring, paying for knowledge/learning, classroom training, on-the-job learning, task force assignments, simulations, and individualized study). Each means of competency development has associated costs in terms of resources and time, as well as associated effectiveness in developing the competencies. In concept, it should be potentially possible to analyze the various combinations of these options to determine the appropriate mix of strategies to accomplish a given competency goal. However, current HRM models and metrics fall short of this goal because they tend to reflect only the costs and activities, rather than their effectiveness. Moreover, the effectiveness of the HRM programs is reflected in measures that are not easily compared (e.g., speed of hiring, turnover rates, numbers of employees trained, etc.). The PeopleVantage model suggests that the solution lies in articulating the linkages. For example, by viewing competencies as one element of PeopleCOM supporting particular value proposition, it is possible to understand the relative value of the competencies, and the tradeoffs in achieving the value proposition. The data to fully "populate" such a model, and carry out all the necessary calculations rarely exist today, but a key first step is to articulate the framework, so that the needed data can be identified. The PeopleVantage model provides that framework, by encouraging organizational leaders to consider HRM as part of the larger value-creation process.

\section{Strategic Goal Setting}

Communicating the linkages described in the PeopleVantage model may have significant and powerful effects on individual behaviors and performance. The "sweeper" example suggests the power of showing even the "anonymous" employees their role in achieving organizational goals, as does the example of Sears, the U.S. retailer, which 
accomplished a significant turnaround by using HR metrics to help employees and managers to more clearly see their role in achieving organizational success (Rucci, Kirn \& Quinn, 1998). We have tantalizing descriptions and evidence that suggest that when the linkages like those in the PeopleVantage model are well understood by managers and employees, their "alignment" with each other and with the goals of the organization lead to higher individual, unit and organizational performance. However, we know little about the mechanisms that create this effect. One promising way to use the PeopleVantage model might be to extend goal setting research similarly to extensions of job satisfaction research noted earlier. Evidence suggests that feedback about performance seems to work through a process of external or internal goal setting, and goal setting is a powerful motivator for enhanced performance (Schultz, Juran \& Boudreau, 1997). Feedback, not accompanied by goals, doesn't lead to improvements in performance unless it suggests self-setting improvement goals (Latham \& Locke, 1991). To date, goal-setting research has focused on job-specific behaviors. Promising new studies might focus on the effectiveness of helping employees set goals that reflect the strategic context. This appears to be precisely what happens when the linkages represented in the PeopleVantage model are articulated, and then supported by communication and organizational systems.

\section{Enhancing Strategic Persuasion and Communication}

Decades of research exist on the factors that enhance the persuasiveness of messages, and their impact on action. Simply put, the theory suggests that the persuasiveness of an argument is in part determined by how much involvement it motivates in the receiver (Petty \& Cacioppo, 1986; Johnson \& Eagly, 1989, 1990). The more involvement, the more the individual "elaborates" upon the message, and the more likely that they will attend to its arguments carefully, and in turn be deeply persuaded by them. Receivers who do not "elaborate" upon a message may process the message more peripherally, relying not on the information provided, but rather on "peripheral" cues such as the professionalism of the messenger, the number of arguments presented, or the forcefulness with which the presenter delivered the message.

From the perspective of the HR metrics, it is possible to consider virtually all HR measurements as some form of persuasive information. Such measures are designed to inform policy-makers, to enhance decisions, or to persuade others to offer support for HR initiatives and programs. When seen within the PeopleVantage model, the purpose of HR metrics is further extended to include informing, enhancing decisions and motivating action 
related to the linkages between HRM and organizational success. When seen in this light, it becomes clear that HRM investments and metrics are likely to be more persuasive when they encompass a wholistic approach such as that depicted in the PeopleVantage model. Typical HR metrics, such as individual performance levels, turnover rates, program costs, numbers of employees with certain characteristics, etc. have little linkage to the context of key constituents. It should not be surprising that they may remain unconvincing or even be ignored. However, when metrics are developed to reflect the PeopleVantage linkages, persuasion theory would seem to suggest that there is greater basis for employees, managers, shareholders and others to engage and elaborate on the message. Each of the links provides more opportunity for constituents to see the relevance of the message to their situation and goals.

Moreover, persuasion theory makes clear that individuals must have the ability to understand a message, for it to motivate elaboration. The PeopleVantage model suggests why HR metrics may often fall short of their purpose. Without an underlying model, it is difficult for constituents to understand the significance of a particular HR metric or investment. This is especially relevant to our earlier discussion regarding financial analysts. While such individuals are undoubtedly highly educated and analytically talented, their cognitive framework may not include the linkages depicted here. Thus, it is difficult to see the relevance of typical reported elements of the organization's human resources. However, using the PeopleVantage model, articulating and even measuring the linkages, provides the basis to help such constituents have the ability to elaborate on the message, understand it, and make better use of the HR metrics they are provided. It seems plausible that enhanced elaboration may be a factor in explaining how such communication works. Future research investigating this may provide useful information about how to enhance the effectiveness of HR metrics.

\section{Conclusion}

This article began with a dilemma: Increasing belief and evidence that HRM investments affect organizational performance, but increasing evidence that financial analysts and others find HR measurements of little use, or even counterproductive. Existing HR measurement systems, including "Balanced Scorecards," "Intellectual Capital", "Behavioral

Costing," and "Utility Analysis" do not seem to have solved the basic problem, that key constituents such as employees, leaders, top managers and the financial community have few

frameworks and very limited data to suggest how human resources affect important organizational outcomes. The PeopleVantage model has been proposed as one framework 
for articulating the key linkages involved in creating value from human capital. This framework is consistent with the premises underlying the different measurement systems, and that it serves to integrate many of their characteristics. By developing HR metrics within this framework, and by conducting future research that links this model to well-studied processes related to information use, such as goal setting, persuasion, optimization and financial reporting, it will be possible to create better understanding and more credibility for HR metrics. 


\section{References}

Amit, R. \& Shoemaker, J.H. (1993). Strategic assets and organizational rents. Strategic Management Journal, 14, 33-46.

Arthur, Jeffrey B. (1992). Effects of human resource systems on manufacturing performance and turnover. Academy of Management Journal, 37, 670-687.

Barney, J. \& Wright, P.M. (1998). "On becoming a strategic partner: The role of human resources in gaining competitive advantage." Human Resource Management, Spring, 37, No. 1, pp. 31-46.

Becker, Brian E. \& Huselid, Mark A. (in press). High performance work systems and firm performance: A synthesis of research and managerial implications. In G. Ferris (ed.) Research in Personnel and Human Resources.

Blumberg, Melvin \& Pringle, Charles D. (1982). The missing opportunity in organizational research: Some implications for a theory of work performance. Academy of Management Review, ㄱ, 560-569.

Boudreau, John W. (1995). "The Motivational Impact of Utility Analysis and HR Measurement." Journal of Human Resource Costing and Accounting, 1, 2, pp. 73-84.

Boudreau, John W. (1991). Utility analysis for decisions in human resource management. In Marvin D. Dunnette \& Leatta M. Hough (Eds.) Handbook of Industrial and Organizational Psychology, (2nd ed.), Vol. 2. Palo Alto: Consulting Psychologists Press, pp. 621-745.

Boudreau, J.W. \& Ramstad, P.R. (in press). "HR Metrics and HR Strategy: Can Metrics Be Strategic?” In P. Wright, L. Dyer, J. Boudreau \& G. Milkovich (Eds.) Strategic Human Resources Management. JAI Press. (CAHRS Working Paper \#98-10.)

Boudreau, John W. \& Ramstad, Peter (1997). "Measuring Intellectual Capital: Learning from Financial History." Human Resource Management, 36, 3, pp. 343-356.

Campbell, John P. \& Pritchard, Robert D. (1976). Motivation theory in Industrial and Organizational psychology. In Marvin D. Dunnette (ed.) Handbook of Industrial and Organizational Psychology.

Carlzon, Jan (1987). Moments of Truth, Cambridge, MA: Ballinger.

Carson, K.P., Becker, J.S. \& Henderson, J.A. (1998). Is utility really futile? Journal of Applied Psychology, 83 (1) 84-96.

Cascio, W. F. (1991). Costing Human Resources (3rd ed.) Wadsworth.

Coff, R. "Human Assets and Management Dilemmas: Coping with Hazards on the Road to Resource-Based Theory", (1997). Academy of Management Review, vol. 22, no. 2, 374402. 
Collis, D.J. (1994). Research note: How valuable are organizational capabilities? Strategic Management Journal, 15, 143-152

Cummings, Lawrence \& Schwab, Donald (1973). Performance in Organizations: Determinants and appraisal..

Dachler, H. Peter \& Mobley, William H. (1973). Construct validation of an instrumentalityexpectancy-task-goal model of work motivation. Journal of Applied Psychology, 58, 397418.

Eccles, Robert G. \& Mavrinac, Sarah C. (1995). Improving the corporate disclosure process. Sloan Management Review, Summer, 11-25.

Economist, June $6^{\text {th }}, 1998$, "A Viking With A Compass" p. 64

Fitz-enz, Jac (1995). How to Measure Human Resource Management (2nd ed.). New York: McGraw-Hill.

Frost, Peter J. (1997). Bridging academia and business: A conversation with Steve Kerr. Organization Science, $\underline{8}$, (3) May-June, 333-347.

Gilbreth, Frank B. (1909). Bricklaying systems. New York: Myron Clark.

Gronroos, Christian (1990) Service Management and Marketing - Managing the Moments of Truth in Service Competition, Massachusetts/Toronto: Lexington Books.

Huselid, Mark A. (1995). The impact of human resource management practices on turnover, productivity, and corporate financial performance. Academy of Management Journal, 38, 635-672.

Ichniowski, Casey, Shaw, Kathryn \& Prennushi, Giovanna (1997). The effects of human resource management practices on productivity: A study of steel finishing lines. American Economic Review 87 (3) 291-313.

Johnson, B.T. \& Eagly, A.H. (1989). Effects of involvement on persuasion: A meta-analysis. Psychological Bulletin, 106, (2), 290-314.

Johnson, B.T. \& Eagly, A.H. (1990). Involvement and persuasion: Types, traditions and the evidence. Psychological Bulletin, 107, (3), 375-384.

Johnson Jeff W. (1996). Linking employee perceptions of service climate to customer satisfaction. Personnel Psychology, Winter, 49, (4) 831-851.

Kamoche, D. (1996). Strategic human resource management within a resource-capability view of the firm. Journal of Management Studies, $\underline{33}, 213-233$.

Kaplan, Robert S. \& Norton, David P. (1996). The balanced scorecard : translating strategy into action. (Boston, Mass. : Harvard Business School Press). 
Klaas, B. \& McClendon J.A. (1996). To lead, lag or match: Estimating the financial impact of pay level policies. Personnel Psychology, 49, 121-141.

Kochan, Thomas (in press). [Title not yet available] In P. Wright, L. Dyer, J. Boudreau \& G. Milkovich (Eds.) Strategic Human Resources Management. JAI Press.

Lado, A.A. \& Wilson, M.C. (1994). Human resource systems and sustained competitive advantage: A competency-based perspective. Academy of Management Review, 19, 699727.

Latham, G. P., \& Locke, E. A. (1991). Self-regulation through goal setting. Organizational Behavior and Human Decision Processes, 50, 212-247.

Latham, Gary \& Whyte, G. (1994). "The Futility of Utility Analysis", Personnel Psychology, vol. 47, pp. 31-46.

Low, Jonathan \& Seisfeld, Tony (1998). Measures that matter. Strategic Leadership, March, 4-28.

Mabon, Hunter (1996). "The Cost of Downsizing in an Enterprise with Job Security", Journal of Human Resource Costing and Accounting, Spring, 1, 1: 35-62.

MacDuffie, John Paul (1995). Human resource bundles and manufacturing performance: Organizational logic and flexible production systems in the world auto industry. Industrial and Labor Relations Review, $\underline{48}$, 197-221.

Maier, Norman R.F. (1955). Psychology in industry.

Milkovich, George T. \& Boudreau, John W. (1997). Personnel/human resource management: A diagnostic approach $\left(8^{\text {th }}\right.$ ed.). Homewood, IL: Richard Irwin, Inc.

Nadler, D. A. (1979). The effects of feedback on task group behavior: A review of the experimental research. Organizational Behavior and Human Performance, 23, 309-338.

Peters, Larry H., \& O'Connor, Edward J.(1980). Situational constraints and work outcomes: The influence of a frequently overlooked construct. Academy of Management Review, $\underline{5}$, 391-397.

Petrash, Gordon (1996). Dow's journey to a knowledge value management culture, European Management Journal, vol. 14, no. 4, August, pp. 365-373.

Petty, R.E. \& Cacioppo, J.W. (986). The elaboration likelihood model of persuasion. In L. Berkowitz (Ed.). Advances in Experimental Social Psychology, vol. 19, 123-205. San Diego, CA: Academic Press.

Pfeffer, Jeffrey (1996). When it comes to "best practices"--Why do smart organizations occasionally do dumb things? Organizational Dynamics Summer 1996 Vol. 25, No. 1 Pg. 33-44. 
Porter, Michael E. (1985). Competitive advantage : creating and sustaining superior performance.. New York : Free Press.

Roos, J. \& von Krogh, G. (1996). The epistemological challenge”, European Management Journal, vol. 14, no. 4, August, 333-337.

Rucci, Anthony J., Kirn, Steven P. \& Quinn, Richard T. (1998). The employee-customer-profit chain at Sears. Harvard Business Review, January-February, 83-97.

Ryan, Ann Marie, Schmit, Mark .J. \& Johnson, Raymond (1996). Attitudes and effectiveness: Examining relations at an organizational level. Personnel Psychology, 49 (94) 853-882. Schmit, Mark J. \& Allscheid, Steven P., (1995). Employee attitudes and customer satisfaction: Making theoretical and empirical connections. Personnel Psychology, 48, (3) 521-536.

Schmit, Mark J. \& Allscheid, Steven P., (1995). Employee attitudes and customer satisfaction: Making theoretical and empirical connections. Personnel Psychology, $\underline{48}$, (3) 521-536.

Schneider, Benjamin, Ashworth, Steven D., Higgs, A. Catherine \& Carr, Linda (1996). Design, validity and use of strategically focused employee attitude surveys. Personnel Psychology, 49, 695-705.

Schultz, K., Juran, D., Boudreau, J.W. (1997). The effects of just-in-time inventory systems on the development of productivity norms. CAHRS Working Paper \#97-17.

Shelby, A.N. (1991). Applying the strategic choice model to motivational appeals: A theoretical approach. The Journal of Business Communication, 28, 187-212.

Shelby, A.N. (1988). A macro theory of management communication. The Journal of Business Communication. 25, 13-27.

Stalk, George, Evans, Philip, \& Shulman, Lawrence E. (1992). Competing on capabilities: The new rules of corporate strategy. Harvard Business Review, March-April, 57-69.

Sveiby, Karl Erik (1997). The New Organizational Wealth. San Francisco: Barrett-Koehler, 1997.

Treacy, Michael \& Wiersema, Fred (1997). The discipline of market leaders. Reading, MA: Addison-Wesley.

Ulrich, Dave. (1998). A new mandate for human resources. Harvard Business Review, January-February, 124-134.

Vroom, Victor (1964). Work and motivation. New York: Wiley.

Welbourne, Theresa W. \& Andrews, Alice O. (1996). Predicting performance of initial public offering firms: Should human resource management be in the equation? Academy of Management Journal, 39 (4), 891-919. 